\title{
Two kinds of short-term memory and the serial position effect ${ }^{\prime}$
}

\author{
STEPHEN BRESKIN, DEPARTMENT OF PSYCHOLOGY, \\ QUEENS COLLEGE OF THE CITY UNIVERSITY OF NEW \\ YORK, Flushing, N.Y. 11367
}

The Ss were required to recall lists of eight letters which were presented either simultaneously or successively. Four rates of presentation were used; each rate for eight different lists. It was found that primacy was operative for successive presentation, and that both primacy and recency were operative for simultaneous presentation.

It has been suggested that the serial position effect of verbal learning and the curves obtained from short-term memory experiments are highly similar. In one experimental study, Crovitz \& Schiffman (1965), obtained a bow-shaped serial position effect for errors when letters were tachistoscopically exposed. They concluded that "...information entering through the visual system is transformed by processes closely associated with learning (p.223)." One purpose of the present study was to examine the serial position effect for two kinds of short-term memory.

Another point of interest was comparison of different types of short-term memory using identical materials. Harcum (1965) states that "...the specific manner in which the individual is presented information for subsequent reproduction does not provide the important variable determining the responses. The most important variables involve the manner in which the subject organizes and stores information in memory (pp. 103-104)."

Filmed presentation of materials made possible two different task situations in the present study. One involved simultaneous presentation of letters to simulate tachistoscopic procedure, while the second presented materials successively as in short-term memory experiments. Since previous work (Mayzner \& Schoenberg, 1965) has found that rate of presentation affects recall, four different rates were employed in comparing the two tasks.

Subjects. Volunteer Ss were chosen from introductory psychology classes at Queens College and were randomly assigned, eight to serve in Experiment 1 and eight to serve in Experiment 2.

Materials. The two experiments, differing in mode of presentation, used identical materials composed of 32 lists, each eight letters long. The lists were generated by use of a table of random numbers with four rates of presentation ( $\left.1 \mathrm{sec}, 1 \frac{1 / 2}{2} \mathrm{sec}, 2 \mathrm{sec}, 2 \frac{1 / 2}{\mathrm{sec}}\right)$ and eight lists for each rate.

Apparatus. For both experiments, the lists were presented on an $8 \mathrm{~mm}$ film.

Procedure. In Experiment 1, the eight letters comprising each list were shown successively. Each letter was exposed at a duration of $1 / 2 \mathrm{sec}$, and then followed by blank periods which, for a given list, were of $1 / 2 \mathrm{sec}, 1 \mathrm{sec}, 1 \frac{1}{2} \mathrm{sec}$, or $2 \mathrm{sec}$ duration. This yielded four rates of presentation: one letter per $1 \mathrm{sec}$, one per $1 \frac{1}{2} \mathrm{sec}$, one per $2 \mathrm{sec}$, and one per $2 \frac{1}{2} \mathrm{sec}$, within the 32 lists. Thus, each rate was presented eight times, arranged in counterbalanced order throughout the 32 lists. Each $S$ was shown the film and was given a response sheet on which the following instructions appeared: "This is an experiment on memory. You will be presented with a series of eight letters. After the cessation of the series you will be given $20 \mathrm{sec}$ to rccord the letters in the order of presentation. If you are not sure, feel free to guess."

It will be noted, that in Experiment 1 the total exposure times for the lists at the four rates were, respectively: $8 \mathrm{sec}, 12 \mathrm{sec}, 16 \mathrm{sec}$, or $20 \mathrm{sec}$. In Experiment 2, the eight letters were presented simultaneously, but at exposure times reduced by a factor of $1 / 4$; that is, for Experiment 2 the times of exposure were $2 \mathrm{sec}, 3 \mathrm{sec}, 4 \mathrm{sec}$, and $5 \mathrm{sec}$. The correction factor was based upon Mackworth's (1962) findings in comparing scores from simultaneous and successive presentation. Aside from these modifications in presentation of the stimuli, the procedure was identical to that of Experiment 1 .

Results and Discussion. The basic data obtained from the Ss were the number of errors, out of a possible eight, at each rate and at each serial position. Since it was advisable to work with logarithms instead of number of errors, a constant of 1 was added throughout the basic data (since at some cells the number of errors for a $S$ was zero). It has been suggested that using logs, instead of number of errors, in measuring the serial position effect, reduces a multiplicative relationship between measures to an additive one (Glanzer \& Peters, 1962).

Figures 1 and 2 are graphs plotting mean logarithms of the number of errors at each serial position. Both graphs show, with the exception of $R_{2}$, a decrease in the curves of errors as rate is increased. Figure 1 shows an increase in errors from beginning to end of serial list, while Fig. 2 shows a slight decrease for the eighth serial position.

The experimental design used permitted analysis of variance to test the effects of serial position, rate, and the interaction of the two. For Experiment 1, significance was found for the effect of serial position $(\mathrm{F}=9.2, \mathrm{df}=7 / 49, \mathrm{p}<.01)$, rate $(\mathrm{F}=9.8, \mathrm{df}=$ $3 / 21, \mathrm{p}<.01)$ and the interaction between the two $(\mathrm{F}=2.0, \mathrm{df}=$ $21 / 147, p<.05$ ). Similarly, for Experiment 2, there was significance in the effect of serial position $(F=12.3, \mathrm{df}=7 / 49, \mathrm{p}<.01)$, rate $(F=6.1, \mathrm{df}=3 / 21, \mathrm{p}<.01)$ and the two-way interaction $(\mathrm{F}=$ $3.6, \mathrm{df}=12 / 147, \mathrm{p}<.01)$. A t test for the difference between the mean logarithm of errors, for the two experiments, showed a significantly lower $(\mathrm{p}<.05)$ mean for Experiment 2. This result was obtained both in total and at each rate.

The serial position effect, obtained in this experiment, shows that primacy was relevant for successive presentation, and that both primacy and recency were relevant for simultaneous presentation. This may reflect a difference in the types of learning required by the tasks. For successive presentation. the $S$ is forced to learn letter 1 , and then letter 2 , etc., on up to letter 8 , and in this sequence. The nature of the task structuring the learning is in favor of a recency principle. For simultaneous presentation, the task is not as structured, and the learner is free to memorize the list in whatever sequence he wishes. However, there is a tendency. due to past experiences, to learn the lists from left to right and, consequently, a bow-shaped curve with primacy being more significant than recency was expected. This result was obtained.

With the exception of $R_{2}$, the expected increase in task difficulty with faster rates of presentation was found. The exception at $R_{2}$, is understandable when the lists presented under this condition are examined. For although the lists were generated by use of random numbers, it appears that the lists under $\mathrm{R}_{2}$ provide an inordinate opportunity to form mnemonics.

The significant interaction between rate and serial position may be an artifact due to the choice of stimuli, rather than to some

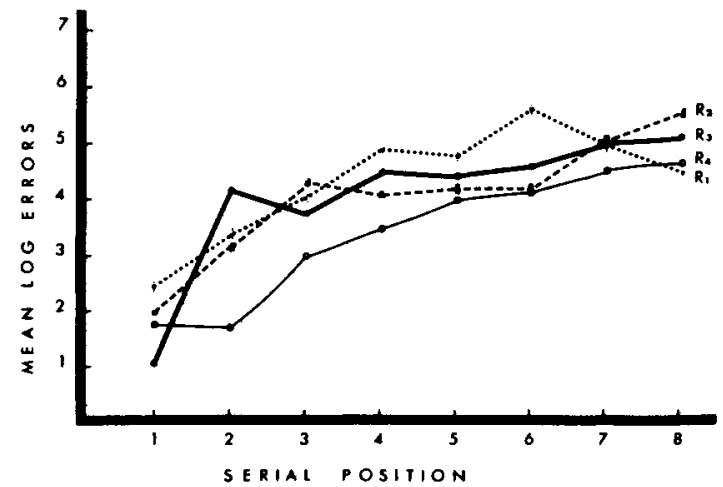

Fig. 1. Mean logarithm of errors as a function of serial position in Experiment 1. 


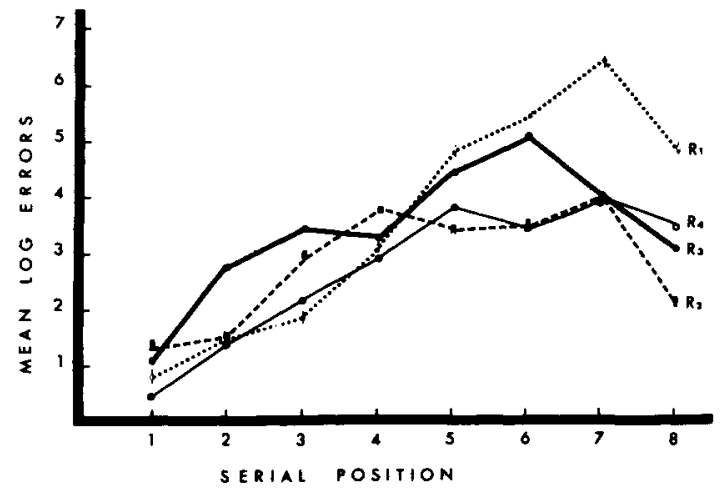

Fig. 2. Mean logarithm of errors as a function of serial position in Experiment 2.

theoretical basis; that is, due to the experimental design, as duration varies, list varies. The attempt to generate equated lists, was not necessarily successful. Thus differences in duration and serial position are dependent upon each other not because changes in duration affect the characteristic shape of the serial position curve, but rather because differences in lists favor differing serial positions.
Another finding was that there were significantly fewer errors for simultaneous presentation even though time for exposure was $1 / 4$ of the time for successive presentation as suggested by Mackworth (1962). She worked with digits rather than letters, and this may account for the discrepancy.

In conclusion, it should be mentioned that although the results are fairly consistent with those hypothesized, further experimentation with a set of lists free of extraneous variables is required.

\section{REFERENCES}

CROVITZ, H. F., \& SCHIFFMAN, H. R. Visual field and letter span. J. exp. Psychol., 1965, 70, 218-223.

GLANZER, M., \& PETERS, S. C. Re-examination of the serial position effect. J. exp. Psychol, 1962, 64, 131-134.

HARCUM, E. R. A curious parallel between serial learning and tachistoscopic perception. Va. J. Sci., 1965, 16, 99-104.

MACKWORTH, J. F. The effect of display time upon recall of digits. Canad. J. Psychol., 16, 48-54.

MAYZNER, M. O., \& SCHOENBERG, K. M. Short-term retention and presentation rate. Psychon. Sci., 1965, 2, 111-112.

\section{NOTE}

1. Supported by a grant (MH 11580-02) from the National Institutes of Health to Wilma A. Winnick, principal investigator. 